\title{
Current progress of fluoroquinolones-increased risk of aortic aneurysm and dissection
}

\author{
Cui Jun ${ }^{1}$ and Bian Fang ${ }^{2^{*}}$ (B)
}

\begin{abstract}
Aortic aneurysm (AA) and aortic dissection (AD) are major life-threatening diseases around the world. AA is a localized or diffuse dilation of the aorta, while $A D$ is the separation of the layers creating a false lumen within the aortic wall. Fluoroquinolones (FQ) remain one of the most important kind of antibiotics and have a wider clinical use and broad antibacterial spectrum. FQ were also reported to treat infected AA. The most common adverse events (AEs) of FQ are mild and reversible, like headaches, diarrhea and nausea. Due to FQ-related serious AEs, such as tendonitis and tendon rupture, chondrotoxicity, or retinal detachment, QT-prolongation and dysglycemia, the United States Food and Drug Administration (FDA) issued a black box warning for FQ for systemic use in 2016 and updated warnings for FQ several times since then. Of note, in December 2018, FDA issued several "black box warnings" against FQ with the latest safety announcement warning about an increased risk of ruptures in the aorta blood vessel in certain patients. Recently, many studies have indicated an association between FQ and an increase risk of AA and AD. However, the exact mechanism of FQ-induced AA/AD remains unclear. This review aims to highlight the latest research progress of the alarming association between FQ and AA/AD. Moreover, molecular mechanisms of FQ in increasing risk of AA and $A D$ are explored. Hopefully, this review can provide novel insights into FQ-increased the risk of AA/AD and a starting place for stewardship interventions.
\end{abstract}

Keywords: Aortic aneurysm, Aortic dissection, Fluoroquinolones, Adverse event

\section{Introduction}

Aortic aneurysm (AA) and aortic dissection (AD) are major life-threatening diseases worldwide. Large AA diameters are associated with increased risk of aneurysm rupture- $\mathrm{AD}$, which is the most devastating complication of aortic diseases. AA is a localized or diffuse dilation of the aorta resulting in at lease a $50 \%$ increase in the aortic diameter, while AD is the separation of the layers creating a false lumen within the aortic wall [1]. Population-based studies reported an annual incidence of AA

\footnotetext{
*Correspondence: bianfang45@sina.com

${ }^{2}$ Department of Pharmacy, Featured Preparations of Vitiligo Xiangyang Key Laboratory, Xiangyang Central Hospital, Affiliated Hospital of Hubei University of Arts and Science, Xiangyang 441000, Hubei, China

Full list of author information is available at the end of the article
}

of 3-13.7/100,000 population, and AD of 3-20/100,000 population [2-4]. Notably, for the elderly population, the annual incidence of AA is much higher at 130/100,000 population [5]. Over the past decades, it is suggested that the rate of mortality from $\mathrm{AA}$ and $\mathrm{AD}$ has risen ranging from 1.2 to 24.8 fold in many developed countries, such as the United States, Britain and Japan [6, 7]. Accordingly to some researches, aortic aneurysm and dissection (AAD) is associated with the weakness of the aortic wall due to congenital defects, prolonged hypertension, or chronic inflammation [1]. In addition, other risk factors including smoking, old age, male sex (men have a fourfold increased risk compared to women) and family history of aortic disease are also implicated in AAD [8]. 
Fluoroquinolones (FQ) are the most widely used prescribed antibiotics in the world. In the United States alone, about 30 million outpatient prescribed with FQ per year [9]. FQ shows activity against both Grampositive and Gram-negative bacteria, and are widely used to treat skin, urinary tract, bone, soft tissue, pulmonary infections and so on. Of note, FQ are also used to treat infected AA $[8,10]$. It is reported that some adverse events (AEs) associated with FQ include tendonitis and tendon rupture, chondrotoxicity, peripheral neuropathy or retinal detachment, QT-prolongation and dysglycemia $[8,11]$. The United States Food and Drug Administration (FDA) issued a black box warning for FQ for systemic use in 2016 and updated warnings for FQ several times since then [8]. Recently, many studies have indicated an association between FQ and an increased risk of AAD $[1,4,9,12]$.

In light of the escalating concerns, the latest research progress of the alarming association between FQ and AAD are summarized. Moreover, molecular mechanisms of FQ in increasing risk of AAD are explored. Hopefully, this review can provide novel insights into FQ-induced the risk of AAD and a starting place for stewardship interventions.

\section{Fluoroquinolones (FQ)}

To our knowledge, FQ remain one of the most important kind of antibiotics used at present around the world. FQ have a wider clinical use and broad antibacterial spectrum against Gram-positive, Gram-negative, aerobic and anaerobic organisms [13]. Additionally, FQ were reported to exert activity on Mycobacterium tuberculosis, which may shorten the duration of treatment and reduce the emergence of bacterial resistance [14]. Besides their typical antibacterial activity, FQ also exhibited diverse atypical biological profiles, like anti-Alzheimer activities [15], anti-tumor [16], anti-malarial [17] and anti-tubercular [18].

Based on their spectrum of activity and their pharmacokinetic profile, FQ are classified into 5 categories. First generation FQ include nalidixic acid, oxolinic acid, pipemidic acid and rosoxacin, which have activity against Gram-negative bacteria [19]. However, they have limited clinical uses because of their short serum half-lives and are only used in Gram-negative bacteria-induced urinary tract infections (UTI) [19]. Second generation FQ contain ciprofloxacin, norfloxacin, enoxacin, pefloxacin, lomefloxacin, nadifloxacin, rufloxacin, and ofloxacin, which have a much wider activity against Gram-negative bacteria including Pseudomonas aeruginosa, and good activity against Gram-positive bacteria. Furthermore, they have longer serum half-lives. They are commonly used in tissue-based diseases, like complicated bladder infections, UTI, sexually transmitted diseases, specific types of pneumonia, pyelonephritis and skin infections [19]. Third generation FQ contain levofloxacin, pazufloxacin, temafloxacin, tosufloxacin, sparfloxacin, grepafloxacin, and balofloxacin, which have a much wider activity against Gram-negative bacteria including $P$. aeruginosa, and good activity against Gram-positive bacteria and anaerobes [20]. Moreover, they have longer serum half-lives. Fourth generation FQ include prulifloxacin, trovafloxacin, alatrofloxacin, delafloxacin, clinafloxacin, besifloxacin, sitafloxacin, finafloxacin, gatifloxacin, gemifloxacin, and moxifloxacin, which have a much wider activity against Gram-positive bacteria, especially Streptococcus pneumoniae and Enterobacteriaceae, good activity against atypical bacteria, and variable activity against anaerobes [21]. In addition, they have longer serum halflives. Of note, they are considered to act at both DNA gyrase and topoisomerase IV and slow down process of bacterial resistance [20]. Fifth generation FQ include levonadifloxacin, nemonoxacin (non-fluorinated quinolone antibiotic), and zabofloxacin, which are undergoing clinical trials. It is suggested that they have higher potency against Gram-positive bacteria with better MIC values and Gram-negative bacteria. Zabofloxacin is considered to be effective in reproductive tract infections and UTI [22].

The most common AEs of FQ are mild and reversible, like headaches, diarrhea and nausea. However, we should pay more attention to FQ-related serious AEs, such as tendinitis and tendon rupture, hepatic toxicity, Clostridium difficile infections, prolonged QT interval, torsades de pointes, phototoxicity, dysglycemia, acute renal failure and seizures $[23,24]$. A systematic review, meta-analysis and network meta-analysis conducted by Matok et al. [25] revealed that there was a significant association between FQ exposure and an increased risk of arrhythmia (85\% increase) and cardiovascular mortality $(71 \%$ increase). Specifically, moxifloxacin was considered to be ranked with the highest probability for arrhythmia and cardiovascular mortality [25]. Of note, in December 2018, FDA issued several "black box warnings" against FQ with the latest safety announcement warning about an increased risk of ruptures in the aorta blood vessel in certain patients.

\section{AAD}

According to anatomical location, AA can be classified into thoracic aortic aneurysm (TAA) and abdominal aortic aneurysm (AAA). TAA exhibits much stronger hereditary and occurs commonly at younger ages with no obvious correlation with gender [26]. For example, some of these familial TAA patients harbor established monogenic forms of disease, like Marfan or Loeys-Dietz 
syndromes. However, it is reported that up to $20 \%$ of individuals with thoracic disease do not have a syndrome but do have related family members with disease (Familial Thoracic Aortic Aneurysm and Dissection or FTAAD) [27]. The risk factors associated with AAA include increasing age, male sex and lifestyle-related risk factors, like smoking, hypertension and hypercholesterolemia, which share many risk factors with atherosclerotic cardiovascular disease [28]. Additionally, inherited factors are also involved in the progression of AAA [29].

Numerous studies have highlighted the critical roles of smooth muscle function and extracellular matrix (ECM) (collagen and elastic fibers) in structural integrity of the arterial wall. Collagen and elastic fibers play important roles in the mechanical properties of the vessel wall. At the pathological level, TAA is characterized by medial degeneration, including elastic fibers fragmentation and loss of elastic tissue, vascular smooth muscle cells (VSMCs) loss, defects in collagen microarchitecture, proteoglycan deposition and a less remarkable inflammatory cells infiltration. Moreover, three important pathological marks are displayed in the progression of AAA: ECM degradation, VSMCs loss and infiltration of macrophages, neutrophils, mast cells and T/B lymphocytes. The imbalance between the production of active martix metalloproteins (MMPs) and their inhibitors (tissue inhibitor of MMPs, TIMPs) would cause the action active of MMPs to mediate ECM degration, which is implicated in the pathogensis of AA. According to the research, the expression of MMP-1, -9, -12, and -14 and MMP-2 were the most notably in the aortic wall of TAA, while MMP$1,-2,-3,-9,-12$, and -13 were increased in AAA [30]. What is more, several studies described MMP-9 for TAA and MMP-3 for AAA as potentially important factors [30]. VSMCs in TAAD changed the phenotype from contractile to synthetic, and enriched with the expression of elastin- and collagen-degrading MMPs at the site of dissection [31]. In addition, lysyl oxidase (LOX) is a copperdependent amine oxidase that catalyzes the formation of cross-linking in collagen fibers and elastic lamellae [27]. $\beta$-Aminopropionitrile (BAPN)-treated animals have been widely used as a model of AAD. As a lathyrogen, BAPN could irreversibly suppress the LOX, thus inhibiting the cross-linking of collagen fibers and elastic lamellae. Lee et al. [32] demonstrated that a missense mutation in LOX would cause AAD in humans.

\section{FQ-increased the risk of AAD}

Recently, lots of laboratory-based studies and clinical studies have raised concern that FQ use could increase the incidence of AAD. Some recent systematic meta-analyses confirmed that there was a strong statistical association between FQ and AAD [12, 33-38]. By comparing with or without FQ exposure in 1 million general population in Taiwan, Lee et al. [1] found an increased risk in AAD with $F Q$ use (rate ratio $[R R]=2.43 ; 95 \%$ confidence interval $[\mathrm{CI}]=1.83-3.22$ ). In the case-crossover study based on a large population-based database, Lee et al. [4] investigated twofold increase the risk of AAD after FQ exposure. In a self-controlled case series analysis, it is revealed that FQ should be used to serious infectious without appropriated alternatives because of its serious cardiovascular adverse events [39].

In a Canadian study, comparing with nonusers, Daneman et al. [40] suggested that FQ induced a similar increased risk of AA or AD. Otherwise, comparing with amoxicillin users, results in a Swedish study revealed that FQ increased a higher risk of AA but not AD [9]. Additionally, The latest study demonstrated that oral FQ were associated with increased incidence of aneurysm formation in United States adults (hazard ratio $[\mathrm{HR}]=1.20$; 95\% CI 1.17-1.24) [41]. A meta-analysis revealed that the risk increase for FQ-induced AA alone was significant (adjusted $\mathrm{RR}=2.23$; 95\% CI 2.01-2.45; I2 $=0 \%$ ). However, the risk increase for FQ-induced $\mathrm{AD}$ alone was not significant (adjusted $R R=1.88$; 95\% CI $0.11-3.65$; $\mathrm{I} 2=74 \%$ ) [33].

\section{Duration of FQ use and the incidence of AAD}

As depicted in Table 1, susceptible period analysis further revealed that current FQ use within 60 days was associated with the highest risk of AAD $[1,4,9,12$, 33, 40]. Lee et al. [4] observed that there was an increased risk of $\mathrm{AAD}$ with prolonged $\mathrm{FQ}$ use $(\mathrm{OR}=2.41$ for 3 - to 14-day exposure; $\mathrm{OR}=2.83$ for $>14$-day exposure; $95 \%$ CI 1.83-3.2). More specifically, FQ use within 60 days was associated with the highest risk of AAD.

Howard et al. [42] found higher risk of AAD was associated with FQ exposure for longer than 14 days $(\mathrm{OR}=2.83$, 95\% CI 1.06-7.57). What is more, Pasternak et al. [9] observed that there was no increased risk of AAD with FQ exposure for more than 60 days (61120 days) ( $\mathrm{HR}=0.67 ; 95 \% \mathrm{CI} 0.40-1.11)$. However, recent results indicated that $\mathrm{FQ}$ were associated with increased 90-day incidence of AAA ( $\mathrm{HR}=1.31 ; 95 \%$ CI 1.25-1.37), iliac artery aneurysm $(\mathrm{HR}=1.60 ; 95 \% \mathrm{CI} 1.33-1.91)$, and other AAA (HR $=1.58$; 95\% CI 1.39-1.79) [41]. Of note, the investigator suggested that FQ should be used with caution in adults, not just in high-risk individuals [41].

\section{Types and dosage forms of FQ use and the incidence of AAD}

As shown in Table 2, ciprofloxacin, levofloxacin, and moxifloxacin are the most commonly prescribed FQ class of antibiotics, which are identified by the FDA and the EMA as being strongly associated with AAD [43]. 
Table 1 Duration of FQ use and the incidence of AAD

\begin{tabular}{|c|c|c|c|c|c|}
\hline Duration of FQ use & No. of participants & OR $(95 \% \mathrm{Cl})$ & outcome & Reference & Study design \\
\hline$\leq 60$ & $\begin{array}{l}1477 \text { case patients and } \\
147,700 \text { matched control } \\
\text { cases }\end{array}$ & $\mathrm{RR}=2.43,95 \% \mathrm{Cl} 1.83-3.22$ & $A A$ or $A D$ & 1 & A nested case-control analysis \\
\hline $3-14$ & $\begin{array}{l}1213 \text { hospitalized AA/AD } \\
\text { patients }\end{array}$ & $\mathrm{OR}=2.41 ; 95 \% \mathrm{Cl} 1.13-3.71$ & & 4 & A case-crossover design \\
\hline \multirow[t]{4}{*}{$\leq 60$} & 360,088 & $\mathrm{HR}=1.66 ; 95 \% \mathrm{Cl} 1.12-2.46$ & $\mathrm{AA}$ or $\mathrm{AD}$ & 9 & $\begin{array}{l}\text { Nationwide historical cohort } \\
\text { study }\end{array}$ \\
\hline & $1,744,360$ & $\begin{array}{l}\text { Adjusted } \mathrm{HR}=2.24,95 \% \mathrm{Cl} \\
2.02-2.49\end{array}$ & AA & 40 & $\begin{array}{l}\text { Population-based longitudinal } \\
\text { cohort study }\end{array}$ \\
\hline & & $\mathrm{RR}=2.14 ; 95 \% \mathrm{Cl} 1.93-2.36$ & $A A$ or $A D$ & 33 & $\begin{array}{l}\text { A systematic review and meta- } \\
\text { analysis }\end{array}$ \\
\hline & $19,207,552$ & $\mathrm{OR}=2.20 ; 95 \% \mathrm{Cl} 1.92-2.52$ & $A A$ or $A D$ & 12 & $\begin{array}{l}\text { Cohort and case-control } \\
\text { studies }\end{array}$ \\
\hline$>14$ & & $\mathrm{OR}=2.83,95 \% \mathrm{Cl} 1.06-7.57$ & AAD & 42 & $\begin{array}{l}\text { A prospective population- } \\
\text { based study }\end{array}$ \\
\hline $14-60$ & $\begin{array}{l}1213 \text { hospitalized AA/AD } \\
\text { patients }\end{array}$ & $\mathrm{OR}=2.83 ; 95 \% \mathrm{Cl} 1.13-3.71$ & $\mathrm{AA}$ or $\mathrm{AD}$ & 4 & A case-crossover design \\
\hline $61-120$ & 360,088 & $\mathrm{HR}=0.67 ; 95 \% \mathrm{Cl} 0.40-1.11$ & None & 9 & $\begin{array}{l}\text { Nationwide historical cohort } \\
\text { study }\end{array}$ \\
\hline \multirow[t]{3}{*}{90} & $27,827,254$ & $\mathrm{HR}=1.31 ; 95 \% \mathrm{Cl} 1.25-1.37$ & AAA & 41 & Cohort study \\
\hline & $27,827,254$ & $\mathrm{HR}=1.60 ; 95 \% \mathrm{Cl} 1.33-1.91$ & Iliac artery aneurysm & 41 & Cohort study \\
\hline & $27,827,254$ & $\mathrm{HR}=1.58 ; 95 \% \mathrm{Cl} 1.39-1.79$ & Other AAA & 41 & Cohort study \\
\hline
\end{tabular}

$F Q$ fluoroquinolones, $O R$ odds ratio, $H R$ hazard ratio, $R R$ adjusted ration, $C l$ confidence interval, $A A$ aortic aneurysm, $A D$ aortic dissection, $A A A$ abdominal aortic aneurysm, $A A D$ aortic aneurysm and dissection

Table 2 Types of FQ use and the incidence of AAD

\begin{tabular}{lll}
\hline FQ & Outcome & References \\
\hline All FQ & AAD & {$[44]$} \\
Ciprofloxacin & AAD & {$[44]$} \\
& AA & {$[45]$} \\
Levofloxacin & AAD & {$[8,44-46]$} \\
& AA & {$[45]$} \\
Moxifloxacin & AAD, AA & {$[44,45]$} \\
& AA & {$[45]$} \\
Ofloxacin & None & {$[44]$} \\
Enoxacin, fleroxacin, gemifloxacin, grepafloxacin, lomefloxacin, norfloxacin, pazufloxacin, & None & {$[46]$} \\
pefloxacin, prulifloxacin, rufloxacin, sparfloxacin, temafloxacin, trovafloxacin & AAD \\
Oral FQ & AAA, iliac artery aneurysm and other \\
Oral FQ & AAA & {$[41]$} \\
\hline
\end{tabular}

$F Q$ fluoroquinolones, $A A$ aortic aneurysm, $A A D$ aortic aneurysm and dissection

In an recent study, Dolladille et al. identified 103 FQrelated AAD reports and a total of 264,917 FQ-related reports. They observed that all FQ $(\mathrm{OR}=1.57 ; 95 \%$ CI 1.12-2.09), ciprofloxacin ( $\mathrm{OR}=2.89 ; 95 \%$ CI $2.24-$ 3.74), levofloxacin ( $\mathrm{OR}=2.89 ; 95 \% \mathrm{CI} 2.24-3.74)$ and moxifloxacin ( $\mathrm{OR}=3.22$; 95\% CI 2.21-4.71) increased the incidence of AAD [44]. Otherwise, there was no significant association of ofloxacin with the risk of AAD $(\mathrm{OR}=0.79 ; 95 \%$ CI 0.33-1.91) [44].

By assessing three FQ (ciprofloxacin, levofloxacin, moxifloxacin)-related AAD from data (2004-2016) mining of the United States Food and Drug Administration Adverse Event Reporting System (FAERS), Sun et al. [45] indicated that they were associated with AA and 
only levofloxacin was associated with $\mathrm{AD}$. Moreover, the incidence of AA was much higher than AD [45]. A case/ non-case study using Vigibase ${ }^{\circledR}$ (2009-2015) observed the highest risk of AAD with levofloxacin [8]. With the Vigibase ${ }^{\circledR}$ between 1972 and 2017, François Montastruc et al. found that only levofloxacin increased the incidence of AAD (OR $=3.25,95 \%$ CI 1.83-4.23) [46]. Additionally, no case of AAD was reported with enoxacin, fleroxacin, gemifloxacin, grepafloxacin, lomefloxacin, norfloxacin, pazufloxacin, pefloxacin, prulifloxacin, rufloxacin, sparfloxacin, temafloxacin, trovafloxacin [46]. In a mouse model of AAD, ciprofloxacin increased the incidence of AAD (38 of 48 [79\%]; $P=0.001 ; X^{2}=10.9$ ), severe AAD (32 of $48[67 \%] ; P<0.001 ; X^{2}=15.7$ ), and rupture and premature death (7 of 48 [15\%]; $P=0.01 ; \chi^{2}=6.0$ ) [47].

Data from FDA adverse event reporting system confirmed that oral FQ was more likely to induce AAD than intravenous administration [45]. In addition, compared with intravenous administration of $\mathrm{FQ}$, oral $\mathrm{FQ}$ were more likely to be implicated in the increased risk of AAD [8]. In the case-crossover study based on a large population-based database, Lee et al. [4] found that oral FQ increased the risk of AAD ( $R R=2.28 ; 95 \%$ CI 1.67-3.13). Consistent with this findings, a nationwide historical cohort study in Sweden (2006-2013) also demonstrated that oral FQ were associated with a $66 \%$ increased rate of AAD [9]. Lee et al. [1] conducted a nested case-control analysis of 1477 case patients and 147,700 matched control cases from Taiwan's National Health Insurance Research Database (NHIRD) from among 1 million individuals longitudinally (2000.1-2011.11), the risk of AAD was increased in patients using oral FQ. Compared with amoxicillin-clavulanate, azithromycin, cephalexin, clindamycin, and sulfamethoxazole-trimethoprim, oral FQ can increase 90-day incidence of AAA $(\mathrm{HR}=1.31$; 95\% CI 1.25-1.37), iliac artery aneurysm $(\mathrm{HR}=1.60 ; 95 \%$ CI 1.33-1.91), and other AAA (HR $=1.58$; 95\% CI 1.391.79) [41]. A recent study confirmed that ciprofloxacin significantly increased the incidence of AAD (79\%) in mice [47].

\section{Users of $F Q$ and incidence of $A A D$}

As depicted in Table 3, nationwide cohort study of adults with pneumonia or UTI results found that an increased relative rate of $\mathrm{AA} / \mathrm{AD}$ associated with $\mathrm{FQ}$ within the pneumonia but not within the UTI [48]. Of note, FQ had an increased risk in AA/AD comparing to azithromycin $(\mathrm{HR}=2.57$; $95 \%$ CI $1.36-4.86$; incidence, $0.03 \%$ for $\mathrm{FQ}$ vs $0.01 \%$ for azithromycin) but no increased rate comparing to combined trimethoprim and sulfamethoxazole $(\mathrm{HR}=0.99 ; 95 \%$ CI $0.62-1.57$; incidence, $<0.01 \%$ in both UTI groups). A recent reported revealed that FQ in patients with AD or AA had a higher risk of all-cause death (adjusted $\mathrm{HR}=1.61$; 95\% CI 1.50-1.73), aortic death (adjusted HR $=1.80 ; 95 \%$ CI $1.50-2.15$ ), and later aortic surgery [49].

By analyzing the hospital admissions data containing information on 22 million adult hospitalizations in the United States from the Advisory Board billing and administrative database (2009-2015), researchers

Table 3 Users of FQ and incidence of AAD

\begin{tabular}{|c|c|c|c|c|}
\hline OR $(95 \% \mathrm{CI})$ & Outcome & Comorbid illnesses & Patient characteristic & References \\
\hline $\mathrm{HR}=2.57 ; 95 \% \mathrm{Cl} 1.36-4.86$ & AAD & Pneumonia & & {$[48]$} \\
\hline $\mathrm{OR}=1.01 ; 95 \% \mathrm{Cl} 0.82-1.24$ & FQ didn't increase the risk of AAD & $\begin{array}{l}\text { Combined amoxi- } \\
\text { cillin-clavulanate or } \\
\text { ampicillin-sulbactam }\end{array}$ & & {$[52]$} \\
\hline $\mathrm{OR}=0.88 ; 95 \% \mathrm{Cl} 0.70-1.11$ & FQ didn't increase the risk of AAD & $\begin{array}{l}\text { Combined with } \\
\text { extended-spectrum } \\
\text { cephalosporins }\end{array}$ & & {$[52]$} \\
\hline Adjusted $H R=2.24 ; 95 \% \mathrm{Cl} 2.02-2.49$ & AA & & Older adults turning 65 years & {$[40]$} \\
\hline $\mathrm{HR}=1.66 ; 95 \% \mathrm{Cl} 1.12-2.46$ & AAD & & Aged 50 years or older & {$[9]$} \\
\hline $\mathrm{RR}=1.72 ; 95 \% \mathrm{Cl} 1.37-2.16$ & AAD & & Older than 70 years & {$[1]$} \\
\hline $\mathrm{HR}=1.18 ; 95 \% \mathrm{Cl} 1.09-1.28$ & AA & & Aged 35 years or older (35-49 years) & {$[41]$} \\
\hline $\mathrm{HR}=1.24 ; 95 \% \mathrm{Cl} 1.19-1.28$ & $\mathrm{AA}$ & & Aged 35 years or older (50-64 years) & {$[41]$} \\
\hline $\mathrm{RR}=1.83 ; 95 \% \mathrm{Cl} 1.27-2.64$ & AAD & & Female patients & {$[1]$} \\
\hline $\mathrm{RR}=1.87 ; 95 \% \mathrm{Cl} 1.24-2.51$ & AAD & & Female patients & {$[33]$} \\
\hline $\mathrm{OR}=0.92 ; 95 \% \mathrm{Cl} 0.46-1.86$ & Intracranial aneurysm or dissection & & & {$[52]$} \\
\hline Adjusted $H R=1.61 ; 95 \% \mathrm{Cl} 1.50-1.73$ & All-cause death & $A A$ or $A D$ & & {$[49]$} \\
\hline Adjusted $\mathrm{HR}=1.80 ; 95 \% \mathrm{Cl} 1.50-2.15$ & Aortic death & $A A$ or $A D$ & & [49] \\
\hline
\end{tabular}


demonstrated that $18 \%$ of the 437,045 patients with AD were exposed to $\mathrm{FQ}$ and $19 \%$ of 27,876 AAD patients received FQ before the aortic repair. In addition, of the 1872 patients with Marfan syndrome, 14\% received FQ during a hospital admission [8]. What's more, Guzzardi et al. [50] suggested that patients with alpha-1 antitrypsin (A1AT) deficiency and longstanding FQ use (26 months) may have a higher risk of AAD.

Daneman et al. [40] observed a two- to threefold increase risk of AA in a larger longitudinal cohort study consisting of more than 1.7 million older adults turning 65 years in Ontario ( $\mathrm{HR}=2.72$; 95\% CI $2.53-2.93$; adjusted $\mathrm{HR}=2.24 ; 95 \% \mathrm{CI} 2.02-2.49$ ). Pasternak et al. [9] also described about twofold increase in AAD in 2.3 million elderly patients (aged 50 years or older) with FQ use comparing to amoxicillin use $(\mathrm{HR}=1.66$; $95 \%$ CI 1.12-2.46). Lee et al. [1] found that the risk increase of AAD was more substantial in patients older than 70 years $(\mathrm{RR}=1.72 ; 95 \% \mathrm{CI} 1.37-2.16)$ than in patients 70 years or younger $(R R=1.46 ; 95 \%$ CI $0.98-2.18)$. And, it was more substantial in female patients $(R R=1.83$; 95\% CI 1.27-2.64) than in male patients $(R R=1.61$; 95\% CI 1.28-2.03) [1]. A meta-analysis revealed that FQ-increased the risk of AAD was higher in females compared to males $(\mathrm{RR}=1.87 ; 95 \%$ CI $1.24-2.51$; $\mathrm{I} 2=0 \%$ versus $\mathrm{RR}=1.58 ; 95 \%$ CI $1.25-1.92 ; \mathrm{I} 2=0 \%$, respectively). What is more, it was higher in older patients compared to younger patients $(\mathrm{RR}=1.72 ; 95 \%$ CI $1.3-2.07$; $\mathrm{I} 2=0 \%$ versus $\mathrm{RR}=1.47$; $95 \%$ CI $0.91-$ 2.04; I $2=0 \%$, respectively) [33]. Otherwise, in a mouse model of AAD, they observed an increased risk of AAD in different aortic segments and no difference between male and female mice [47]. The latest study demonstrated that oral FQ were associated with increased incidence of aneurysm formation in United States adults $(\mathrm{HR}=1.20 ; 95 \% \mathrm{CI} 1.17-1.24)$ [41]. More specifically, adults aged 35 years or older had an increased risk in AA (18-34 years: $\mathrm{HR}=0.99$; $95 \%$ CI $0.83-1.18$; 35-49 years: $\mathrm{HR}=1.18 ; 95 \% \mathrm{CI} 1.09-1.28 ; 50-64$ years: $\mathrm{HR}=1.24 ; 95 \% \mathrm{CI} 1.19-1.28 ; P=0.04)$ [41].

Of course, there are different points of view in some studies. Relative to combined amoxicillin-clavulanate or combined ampicillin-sulbactam $(\mathrm{OR}=1.01 ; 95 \% \mathrm{CI}$ $0.82-1.24)$ or with extended-spectrum cephalosporins $(\mathrm{OR}=0.88$; 95\% CI 0.70-1.11) among patients with indicated infections, Dong et al. [51] observed that FQ didn't increase the risk of AAD in a nested case-control study. A case-time-control study was performed with French National Insurance databases covering $>60$ million inhabitants. Comparing with amoxicillin $(\mathrm{OR}=0.97$; 95\% CI 0.61-1.53), there was no an excess of risk of intracranial aneurysm or dissection with FQ exposure $(\mathrm{OR}=0.92 ; 95 \%$ CI $0.46-1.86)$ [52].

\section{Genetic predisposition and FQ-induced increased risk of AAD}

According to some finds, there are multiple genetic syndromes associated with aortic aneurysmal disease, such as Marfan syndrome (FBN1), Ehlers-Danlos syndrome (COL5A1, COL5A2, COL3A1), Loeys-Dietz syndrome (TGFBR1, TGFBR2), FTAAD (TGFBR2, MYH1, $A C T A 2)$, and autosomal dominant polycystic kidney disease (PDK1, PKD2) [53]. Genetic studies explored that ciprofloxacin-associated neuropsychiatric toxicities may related to one specific CYP450 gene in patients [54]. Of note, Guzzardi et al. [50] suggested that patients with alpha-1 antitrypsin (A1AT) deficiency and longstanding FQ use (26 months) may have a higher risk of AAD. However, there are a few reports about genetic predisposition and FQ-induced increased risk of AAD.

\section{Mechanisms of FQ-induced AAD}

The exact mechanism of FQ-induced AAD remains unclear. Some hypothesized biological mechanisms have been proposed, as depicted in Fig. 1.

FQ may interfere with ECM integrity in the aortas. Dysregulation of ECM homeostasis disrupted ECM integrity and impaired biomechanical strength, which finally triggered progressive aortic weakening, dissection, or rupture [55]. According to some studies, enzymatic degradation of ECM by MMPs and vascular remodeling constituted the most prominent characters of AA [56]. However, TIMPs may inhibit the development of AA. Evidence confirmed that FQ reduced collagen production in tenocytes [57] and fibroblasts [58]. Plenty of researches showed that ciprofloxacin (the most commonly used FQ) suppressed TIMP-1 expression but enhanced MMP expression in the cornea [59], in tendon cells and tissues $[57,60]$, and in fibroblasts [61], which finally promoted MMP activation and tissue destruction.

It was suggested that ciprofloxacin greatly up-regulated MMP activity more than twofold in cultured human aortic smooth muscle cells (HASMCs) [62]. Human aortic fibroblasts exposed to FQ showed an increased capacity for ECM dysregulation by reducing the expression of collagen and endogenous protease inhibitors protein. They further demonstrated collagen degradation and decreased TIMPs activity in human aortic fibroblasts cultured with 2 days FQ [63]. A recent study confirmed that ciprofloxacin significantly increased the incidence of AAD (79\%) in mice [47]. Specifically, in the mouse model of AAD that ciprofloxacin exposure reduced the expression of LOX, an critical enzyme in the assembly and stabilization of elastic fibers and collagen. Meantime, ciprofloxacin us enhanced MMP expression and activity as well as elastic fiber fragmentation in the aortas. Furthermore, in 


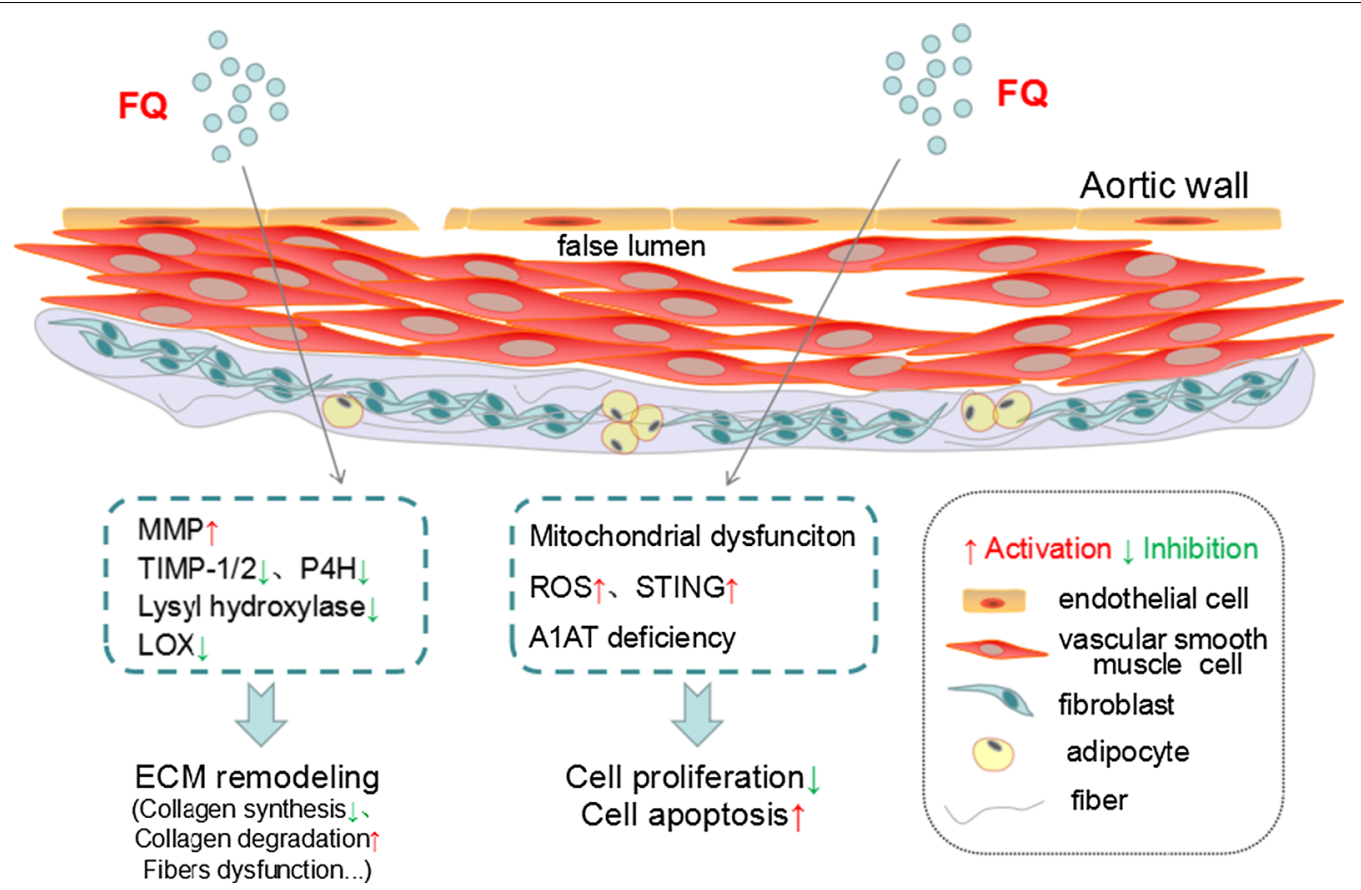

Fig. 1 Mechanisms of FQ-induced AAD. FQ induces ECM remodeling via promoting MMP activation and inhibiting TIMP-1/2, P4H, Lysyl hydroxylase and LOX. FQ decreases cell proliferation and increases cell apoptosis through promoting mitochondrial dysfunction, ROS production, activation of STING. Patients with A1AT deficiency may associated with FQ-induced AAD. FQ fluoroquinolones, MMP martix metalloprotein, TIMP tissue inhibitors of matrix metalloproteinase, $P 4 H$ prolyl 4-hydroxylase, LOX lysyl oxidase, ROS reactive oxygen species, STING stimulator of interferon genes, ATAT alpha-1 antitrypsin, ECM extracellular matrix, AAD aortic aneurysm and dissection

cultured smooth muscle cells, ciprofloxacin markedly down-regulated LOX levels and activity while up-regulated MMP levels.

Myofibroblasts have an abundant cell population in the aortic wall adventitia and have a capacity for structural arterial ECM remodeling. Another recent study found that FQ exposure induced an imbalance of ECM regulatory processes and enhance the capacity of human aortic myofibroblasts for ECM remodeling [64]. In addition, ciprofloxacin greatly reduced TIMP1 and TIMP2 expression while induced MMP9 to TIMP2 ration and collagen-1 expression in cultured human aortic myofibroblasts [64].

To our knowledge, FQ is considered to be powerful iron chelators. Prolyl 4-hydroxylase (P4H) and lysyl hydroxylase are iron-dependent enzymes, which play central roles in the post-translational modification of collagen. These enzymes promote collagen maturation through hydroxylation of proline and lysine residues to induce collagen cross-linking, which is essential for the tensile strength of collagen fibers. Badal et al. [65] demonstrated that FQ (norfloxacin, ciprofloxacin, enrofloxacin)-meidated iron chelation suppressed collagen maturation by inhibiting $\mathrm{P} 4 \mathrm{H}$ and lysyl hydroxylase. FQ also exerted chelating properties against some other ions, including magnesium [66, 67] and calcium [67], which finally influenced collagen synthesis.

In addition, the effect of FQ on the inhibition of cell proliferation and induction of cell apoptosis may lead to aortic destruction. Evidence showed that FQ inhibited cell proliferation in various cells, including tenocytes [68], osteoblasts [69] and chondrocytes [70], and induced cell apoptosis in various cells, like tenocytes [57] and lens epithelial cells [71]. A recent study found that ciprofloxacin induced aortic cell injury in the aortas in a mouse model of AAD [47]. Furthermore, ciprofloxacin suppressed cell proliferation and promoted cell death in cultured HASMCs [47]. Mechanically, as a DNA topoisomerase inhibitor, ciprofloxacin induced nuclear and mitochondrial DNA damage and the the release of DNA, which finally promoted mitochondrial dysfunction, reactive oxygen species (ROS) production, activation of STING (stimulator of interferon genes, the cytosolic DNA sensor) and cell death [47]. However, in cultured human aortic myofibroblasts, ciprofloxacin exerted no significant effects on cell apoptosis, necrosis and metabolic viability [64]. 


\section{Conclusion and future prospects}

According to the studies, exposure to FQ is substantially associated with the increase risk of AAD. Given the global burden of AAD and the growing FQ use around the world, well-designed studies in populations, especially high-risk populations, should be conducted. It is worthy to launch animal studies to clarify the pathophysiological mechanism of this association. What is more, it would be especially important to illustrate how FQ interact with the aortas. Better and direct understanding of the exact mechanism of FQ-induced AAD is imperative and essential. The last, but not the least, clinicians should carefully consider and balance the risks of AAD associated with FQ exposure against their established benefits.

\begin{abstract}
Abbreviations
AA: Aortic aneurysm; AD: Aortic dissection; FQ: Fluoroquinolone; AEs: Adverse events; FDA: Food and Drug Administration; TAA: Thoracic aortic aneurysm; AAA: Abdominal aortic aneurysm; FTAAD: Familial Thoracic Aortic Aneurysm and Dissection; ECM: Extracellular matrix; VSMCs: Vascular smooth muscle cells; MMPs: Martix metalloproteins; BAPN: $\beta$-Aminopropionitrile; FAERS: Food and Drug Administration Adverse Event Reporting System; HASMCs: Human aortic smooth muscle cells.
\end{abstract}

\section{Acknowledgements}

Not applicable.

\section{Authors' contributions}

CJ was a major contributor in writing the manuscript. BF was a supervisor in the manuscript.

\section{Funding}

This work was supported by grants from the Natural Science Foundation of Hubei Province (2020CFB720), Hubei Province health and family planning scientific research project (WJ2019F085) and Xiangyang Science and Technology Planning project (2020YL34, 2020YL35).

\section{Availability of data and materials}

Not applicable.

\section{Declarations}

Ethics approval and consent to participate

Not applicable.

\section{Consent for publication}

Not applicable.

\section{Competing interests}

The authors have no conflict of interest that are directly relevant to the content of this article.

\section{Author details}

${ }^{1}$ Department of Cardiothoracic Surgery, Xiangyang Central Hospital, Affiliated Hospital of Hubei University of Arts and Science, Xiangyang 441000, Hubei, China. ${ }^{2}$ Department of Pharmacy, Featured Preparations of Vitiligo Xiangyang Key Laboratory, Xiangyang Central Hospital, Affiliated Hospital of Hubei University of Arts and Science, Xiangyang 441000, Hubei, China.

Received: 20 January 2021 Accepted: 8 September 2021 Published online: 28 September 2021

\section{References}

1. Lee CC, Lee MT, Chen YS, Lee SH, Chen SC, Chang SC. Risk of aortic dissection and aortic aneurysm in patients taking oral fluoroquinolone. JAMA Intern Med. 2015;175(11):1839-47.

2. Howard DP, Banerjee A, Fairhead JF, Perkins J, Silver LE, Rothwell PM. Population-based study of incidence and outcome of acute aortic dissection and premorbid risk factor control: 10-year results from the Oxford Vascular Study. Circulation. 2013;127(20):2031-7.

3. Wang SW, Huang YB, Huang JW, Chiu CC, Lai WT, Chen CY. Epidemiology, clinical features, and prescribing patterns of aortic aneurysm in Asian population from 2005 to 2011. Medicine. 2015;94(41):e1716.

4. Lee CC, Lee MG, Hsieh R, Porta L, Lee WC, Lee SH, Chang SS. Oral fluoroquinolone and the risk of aortic dissection. J Am Coll Cardiol. 2018;72(12):1369-78.

5. Howard DP, Banerjee A, Fairhead JF, Handa A, Silver LE, Rothwell PM Population-based study of incidence of acute abdominal aortic aneurysms with projected impact of screening strategy. J Am Heart Assoc. 2015:4(8):e001926.

6. Sampson UK, Norman PE, Fowkes FG, Aboyans V, Yanna S, Harrell FE Jr, Forouzanfar MH, Naghavi M, Denenberg JO, McDermott MM, Criqui MH, Mensah GA, Ezzati M, Murray C. Global and regional burden of aortic dissection and aneurysms: mortality trends in 21 world regions, 1990 to 2010. Glob Heart. 2014;9(1):171-80e10.

7. Sidloff D, Choke E, Stather P, Bown M, Thompson J, Sayers R. Mortality from thoracic aortic diseases and associations with cardiovascular risk factors. Circulation. 2014;130(25):2287-94

8. Frankel WC, Trautner BW, Spiegelman A, Grigoryan L, LeMaire SA. Patients at risk for aortic rupture often exposed to fluoroquinolones during hospitalization. Antimicrob Agents Chemother. 2019;63(2):e01712-18.

9. Pasternak B, Inghammar M, Svanstrom H. Fluoroquinolone use and risk of aortic aneurysm and dissection: nationwide cohort study. BMJ. 2018;360:k678.

10. Linder JA, Huang ES, Steinman MA, Gonzales R, Stafford RS. Fluoroquinolone prescribing in the United States: 1995 to 2002. Am J Med. 2005;118(3):259-68

11. Jackson MA, Schutze GE. The use of systemic and topical fluoroquinolones. Pediatrics. 2016;138(5):e1034-45.

12. Yu X, Jiang DS, Wang J, Wang R, Chen T, Wang K, Cao S, Wei X. Fluoroquinolone use and the risk of collagen-associated adverse events: a systematic review and meta-analysis. Drug Saf. 2019;42:1025-33.

13. Ezelarab HAA, Abbas SH, Hassan HA, Abuo-Rahma GEA. Recent updates of fluoroquinolones as antibacterial agents. Arch Pharm. 2018;351(9):e1800141.

14. Drobac PC, del Castillo H, Sweetland A, Anca G, Joseph JK, Furin J, Shin S. Treatment of multidrug-resistant tuberculosis during pregnancy: longterm follow-up of 6 children with intrauterine exposure to second-line agents. Clin Infect Dis Off Publ Infect Dis Soc Am. 2005;40(11):1689-92.

15. Pudlo M, Luzet V, Ismaili L, Tomassoli I, lutzeler A, Refouvelet B. Quinolonebenzylpiperidine derivatives as novel acetylcholinesterase inhibitor and antioxidant hybrids for Alzheimer disease. Bioorg Med Chem. 2014;22(8):2496-507.

16. Abdel-Aziz M, Park SE, Abuo-Rahma Gel D, Sayed MA, Kwon Y. Novel $\mathrm{N}$-4-piperazinyl-ciprofloxacin-chalcone hybrids: synthesis, physicochemical properties, anticancer and topoisomerase I and II inhibitory activity. Eur J Med Chem. 2013;69:427-38.

17. Li J, Li S, Bai C, Liu H, Gramatica P. Structural requirements of 3-carboxyl$4(1 \mathrm{H})$-quinolones as potential antimalarials from 2D and 3D QSAR analysis. J Mol Graph Model. 2013;44:266-77.

18. Shandil RK, Jayaram R, Kaur P, Gaonkar S, Suresh BL, Mahesh BN, Jayashree $R$, Nandi V, Bharath S, Balasubramanian V. Moxifloxacin, ofloxacin, sparfloxacin, and ciprofloxacin against Mycobacterium tuberculosis: evaluation of in vitro and pharmacodynamic indices that best predict in vivo efficacy. Antimicrob Agents Chemother. 2007;51(2):576-82.

19. Koba M, Baczek T, Macur K, Bober L, FrackowiakT, Bucinski A, RystokGrabska D, Stasiak J, Koba K. Factor analysis of microbiological activity data and structural parameters of antibacterial quinolones. J Mol Model. 2010;16(2):327-35.

20. Zhang GF, Zhang S, Pan B, Liu X, Feng LS. 4-Quinolone derivatives and their activities against Gram positive pathogens. Eur J Med Chem. 2018;1(143):710-23. 
21. Lan NT, Lien HT, le Tung B, Borgdorff MW, Kremer K, van Soolingen D. Mycobacterium tuberculosis Beijing genotype and risk for treatment failure and relapse, Vietnam. Emerg Infect Dis. 2003;9(12):1633-5.

22. Zhang GF, Liu X, Zhang S, Pan B, Liu ML. Ciprofloxacin derivatives and their antibacterial activities. Eur J Med Chem. 2018;25(146):599-612.

23. Liu HH. Safety profile of the fluoroquinolones: focus on levofloxacin. Drug Saf. 2010;33(5):353-69.

24. Kuula LSM, Viljemaa KM, Backman JT, Blom M. Fluoroquinolone-related adverse events resulting in health service use and costs: a systematic review. PLoS ONE. 2019;14(4):e0216029.

25. Gorelik E, Masarwa R, Perlman A, Rotshild V, Abbasi M, Muszkat M, Matok I. Fluoroquinolones and cardiovascular risk: a systematic review, meta-analysis and network meta-analysis. Drug Saf. 2019;42(4):529-38.

26. Olsson C, Granath F, Stahle E. Family history, comorbidity and risk of thoracic aortic disease: a population-based case-control study. Heart. 2013:99(14):1030-3.

27. Lin CJ, Lin CY, Stitziel NO. Genetics of the extracellular matrix in aortic aneurysmal diseases. Matrix Biol J Int Soc Matrix Biol. 2018;71-72:128-43.

28. Forsdahl SH, Singh K, Solberg S, Jacobsen BK. Risk factors for abdominal aortic aneurysms: a 7-year prospective study: the Tromso Study, 1994-2001. Circulation. 2009;119(16):2202-8.

29. Larsson E, Granath F, Swedenborg J, Hultgren R. A population-based case-control study of the familial risk of abdominal aortic aneurysm. J Vasc Surg. 2009:49(1):47-50 (discussion 1).

30. Wang Q, Ding Y, Song P, Zhu H, Okon I, Ding YN, Chen HZ, Liu DP, Zou $\mathrm{MH}$. Tryptophan-derived 3-hydroxyanthranilic acid contributes to angiotensin II-induced abdominal aortic aneurysm formation in mice in vivo. Circulation. 2017:136(23):2271-83.

31. Ishii T, Asuwa N. Collagen and elastin degradation by matrix metalloproteinases and tissue inhibitors of matrix metalloproteinase in aortic dissection. Hum Pathol. 2000;31 (6):640-6.

32. Lee VS, Halabi CM, Hoffman EP, Carmichael N, Leshchiner I, Lian CG, Bierhals AJ, Vuzman D, Mecham RP, Frank NY, Stitziel NO. Loss of function mutation in LOX causes thoracic aortic aneurysm and dissection in humans. Proc Natl Acad Sci USA. 2016;113(31):8759-64.

33. Rawla P, Helou MLE, Vellipuram AR. Fluoroquinolones and the risk of aortic aneurysm or aortic dissection: a systematic review and metaanalysis. Cardiovasc Hematol Agents Med Chem. 2019;17:3-10.

34. Singh S, Nautiyal A. Aortic dissection and aortic aneurysms associated with fluoroquinolones: a systematic review and meta-analysis. Am J Med. 2017;130(12):1449-57.

35. Noman AT, Qazi AH, Alqasrawi M, Ayinde H, Tleyjeh IM, Lindower P, Bin Abdulhak AA. Fluoroquinolones and the risk of aortopathy: a systematic review and meta-analysis. Int J Cardiol. 2019;1 (274):299-302.

36. Vouga Ribeiro N, Gouveia Melo R, Guerra NC, Nobre Â, Fernandes RM, Pedro LM, Costa J, Pinto FJ, Caldeira D. Fluoroquinolones are associated with increased risk of aortic aneurysm or dissection: systematic review and meta-analysis. Semin Thorac Cardiovasc Surg. 2020.

37. Dai XC, Yang XX, Ma L, Tang GM, Pan YY, Hu HL. Relationship between fluoroquinolones and the risk of aortic diseases: a meta-analysis of observational studies. BMC Cardiovasc Disord. 2020;201(1):1-8.

38. Wee I, Chin B, Syn N, et al. The association between fluoroquinolones and aortic dissection and aortic aneurysms: a systematic review and meta-analysis. Sci Rep. 2021;11(1):1-11.

39. Aspinall SL, Sylvain NP, Zhao X, Zhang R, Dong D, Echevarria K, Glassman PA, Goetz MB, Miller DR, Cunningham FE. Serious cardiovascular adverse events with fluoroquinolones versus other antibiotics: a self-controlled case series analysis. Pharmacol Res Perspect. 2020;86(6):e00664

40. Daneman N, Lu H, Redelmeier DA. Fluoroquinolones and collagen associated severe adverse events: a longitudinal cohort study. BMJ Open. 2015;5(11):e010077.

41. Newton ER, Akerman AW, Strassle PD, Kibbe MR. Association of fluoroquinolone use with short-term risk of development of aortic aneurysm. JAMA Surg. 2021:156:264-72.

42. Howard DP, Banerjee A, Fairhead JF, et al. Age-specific incidence, risk factors and outcome of acute abdominal aortic aneurysms in a defined population. Br J Surg. 2015;102(8):907-15.

43. Bennett $A C$, Bennett $C L$, Witherspoon BJ, et al. An evaluation of reports of ciprofloxacin, levofloxacin, and moxifloxacin-association neuropsychiatric toxicities, long-term disability, and aortic aneurysms/dissections disseminated by the Food and Drug Administration and the European Medicines Agency. Expert Opin Drug Saf. 2019;18(11):1055-63.

44. Dolladille C, Chrétien B, Sassier M, et al. Fluoroquinolone and aortic dissection: is it a class effect? J Am Coll Cardiol. 2019;73(3):382-3.

45. Meng L, Huang J, Jia Y, Huang H, Qiu F, Sun S. Assessing fluoroquinoloneassociated aortic aneurysm and dissection: data mining of the public version of the FDA adverse event reporting system. Int J Clin Pract. 2019:73(5):e13331.

46. Sommet A, Bénévent J, Rousseau V, et al. What fluoroquinolones have the highest risk of aortic aneurysm? A case/non-case study in vigiBase ${ }^{\circledR}$. Soc Gen Intern Med. 2019;34(4):502-3.

47. LeMaire SA, Zhang L, Luo W, Ren P, Azares AR, Wang Y, Zhang C, Coselli JS, Shen YH. Effect of ciprofloxacin on susceptibility to aortic dissection and rupture in mice. JAMA Surg. 2018;153(9):e181804.

48. Gopalakrishnan C, Bykov K, Fischer MA, Connolly JG, Gagne JJ, Fralick M. Association of fluoroquinolones with the risk of aortic aneurysm or aortic dissection. JAMA Intern Med. 2020;180:1596-605.

49. Chen SW, Chan YH, Chien-Chia Wu V, et al. Effects of fluoroquinolones on outcomes of patients with aortic dissection or aneurysm. J Am Coll Cardiol. 2021;77(15):1875-87.

50. Guzzardi DG, Hassanabad AF, Bromley AB, et al. Fluoroquinoloneassociated type $\mathrm{A}$ aortic dissection in alpha-1 anti-trypsin deficiency. Ann Thorac Sur. 2020:110(6):e489-91.

51. Dong $\mathrm{YH}$, Chang $\mathrm{CH}$, Wang $\mathrm{JL}$, et al. Association of infections and use of fluoroquinolones with the risk of aortic aneurysm or aortic dissection. JAMA Intern Med. 2020;180(12):1587-95.

52. Maumus-Robert S, Debette S, Bérard X, et al. Risk of intracranial aneurysm and dissection and fluoroquinolone use: a case-time-control study. Stroke. 2020;51(3):994-7.

53. Cury M, Zeidan F, Lobato AC, et al. Aortic disease in the young: genetic aneurysm syndromes, connective tissue disorders, and familial aortic aneurysms and dissections. Int J Vasc Med. 2013;2013:267215.

54. Bennett A, Qureshi ZP, Bennett CL. A novel genetic marker has been identified in patients with fluoroquinolone-associated neuropyschiatric toxicity: preliminary findings. Federal Pract. 2017; 330

55. Hoefer IE, den Adel B, Daemen MJ. Biomechanical factors as triggers of vascular growth. Cardiovasc Res. 2013;99(2):276-83.

56. Hadi T, Boytard L, Silvestro M, Alebrahim D, Jacob S, Feinstein J, Barone K, Spiro W, Hutchison S, Simon R, Rateri D, Pinet F, Fenyo D, Adelman M, Moore KJ, Eltzschig HK, Daugherty A, Ramkhelawon B. Macrophagederived netrin-1 promotes abdominal aortic aneurysm formation by activating MMP3 in vascular smooth muscle cells. Nat Commun. 2018;9(1):5022.

57. Sendzik J, Shakibaei M, Schafer-Korting M, Lode H, Stahlmann R. Synergistic effects of dexamethasone and quinolones on human-derived tendon cells. Int J Antimicrob Agents. 2010;35(4):366-74.

58. Orobello NC, Dirain CO, Schultz G, Milne-Davies BA, Ng MR, Antonelli PJ. Ciprofloxacin decreases collagen in mouse tympanic membrane fibroblasts. Otolaryngol Head Neck Surg Off J Am Acad Otolaryngol Head Neck Surg. 2016;155(1):127-32.

59. Sharma C, Velpandian T, Baskar Singh S, Ranjan Biswas N, Bihari Vajpayee $\mathrm{R}$, Ghose $\mathrm{S}$. Effect of fluoroquinolones on the expression of matrix metalloproteinase in debrided cornea of rats. Toxicol Mech Methods. 2011;21(1):6-12.

60. Tsai WC, Hsu CC, Chen CP, Chang HN, Wong AM, Lin MS, Pang JH. Ciprofloxacin up-regulates tendon cells to express matrix metalloproteinase-2 with degradation of type I collagen. J Orthop Res Off Publ Orthop Res Soc. 2011;29(1):67-73.

61. Bujor AM, Haines P, Padilla C, Christmann RB, Junie M, Sampaio-Barros PD, Lafyatis R, Trojanowska M. Ciprofloxacin has antifibrotic effects in scleroderma fibroblasts via downregulation of Dnmt1 and upregulation of Fli1. Int J Mol Med. 2012;30(6):1473-80.

62. Wang D, Jahangir A, Tajik JK. Ciprofloxacin enhances matrix metalloproteinases activity in human ASMCs. J Patient-Centered Res Rev. 2014;1:58-9.

63. Guzzardi D, Teng G, Svystonyuk D. Fluoroquinolone induces human aortic fibroblast mediated extracellular matrix dysregulation. Can J Cardiol. 2017:33:38-9.

64. Guzzardi DG, Teng G, Kang S, Geeraert PJ, Pattar SS, Svystonyuk DA, Belke DD, Fedak PWM. Induction of human aortic 
myofibroblast-mediated extracellular matrix dysregulation: a potential mechanism of fluoroquinolone-associated aortopathy. J Thorac Cardiovasc Surg. 2019;157(1):109-19e2.

65. Badal $S$, Her YF, Maher $\sqcup$ 3rd. Nonantibiotic effects of fluoroquinolones in mammalian cells. J Biol Chem. 2015;290(36):22287-97.

66. Shakibaei M, Pfister K, Schwabe R, Vormann J, Stahlmann R. Ultrastructure of Achilles tendons of rats treated with ofloxacin and fed a normal or magnesium-deficient diet. Antimicrob Agents Chemother. 2000:44(2):261-6.

67. Stahlmann R, Kuhner S, Shakibaei M, Flores J, Vormann J, van Sickle DC. Effects of magnesium deficiency on joint cartilage in immature beagle dogs: immunohistochemistry, electron microscopy, and mineral concentrations. Arch Toxicol. 2000;73(10-11):573-80.

68. Tsai WC, Hsu CC, Chen HC, Hsu YH, Lin MS, Wu CW, Pang JH.

Ciprofloxacin-mediated inhibition of tenocyte migration and downregulation of focal adhesion kinase phosphorylation. Eur J Pharmacol. 2009;607(1-3):23-6.
69. Li P, Cheng NN, Chen BY, Wang YM. In vivo and in vitro chondrotoxicity of ciprofloxacin in juvenile rats. Acta Pharmacol Sin. 2004;25(10):1262-6.

70. Williams RJ 3rd, Attia E, Wickiewicz TL, Hannafin JA. The effect of ciprofloxacin on tendon, paratenon, and capsular fibroblast metabolism. Am J Sports Med. 2000;28(3):364-9.

71. Zhao B, Chignell CF, Rammal M, Smith F, Hamilton MG, Andley UP, Roberts JE. Detection and prevention of ocular phototoxicity of ciprofloxacin and other fluoroquinolone antibiotics. Photochem Photobiol. 2010;86(4):798-805.

\section{Publisher's Note}

Springer Nature remains neutral with regard to jurisdictional claims in published maps and institutional affiliations.
Ready to submit your research? Choose BMC and benefit from:

- fast, convenient online submission

- thorough peer review by experienced researchers in your field

- rapid publication on acceptance

- support for research data, including large and complex data types

- gold Open Access which fosters wider collaboration and increased citations

- maximum visibility for your research: over $100 \mathrm{M}$ website views per year

At BMC, research is always in progress.

Learn more biomedcentral.com/submissions 